\title{
Parent Training and Behavior Therapy on Behaviors of Children With Attention Deficit-Hyperactivity Disorder
}

\author{
Mahvash Raghibi ${ }^{1}$; Samaneh Fouladi ${ }^{1,}$; Nour Mohammad Bakhshani ${ }^{2}$ \\ ${ }^{1}$ Department of Psychology, Faculty of Education and Psychology, Sistan and Baluchestan University, Zahedan, IR Iran \\ ${ }^{2}$ Department of Clinical Psychology, Zahedan University of Medical Sciences and Health Services, Zahedan, IR Iran \\ ${ }^{*}$ Corresponding author: Samaneh Fouladi, Department of Psychology, Faculty of Education and Psychology, Sistan and Baluchestan University, Zahedan, IR Iran. Tel: +98-5412416143, \\ Fax:+98-5412416143, E-mail: samanehfouladi@gmail.com
}

Received: October 15, 2013; Revised: January 1, 2014; Accepted: January 15, 2014

\begin{abstract}
Background: Attention deficit-hyperactivity disorder (ADHD) is a neurobehavioral condition characterized by poor attention, hyperactivity and misbehavior. Parent training and behavioral therapy are psychosocial techniques aimed at training parents to manage and change their children's behavior.

Objectives: This study examined the impact of parent training and behavioral therapy to control ADHD children.

Patients and Methods: This research was a pretest-posttest study, conducted on 61 ADHD children selected randomly among referrals to psychological clinic (Hamdelan) Zahedan, Iran in 2010. Eight sessions of parent training based on the Barkley method and eight sessions of behavioral therapy were held for children's parents. The measurement tool was a researcher made questionnaires, consisting of diagnostic symptoms and features of ADHD based on DSM IV (diagnostic and statistical manual of mental disorders). Data were analyzed using t-test and SPSS software version 17.

Results: Nine girls (14.8\%) and 52 boys (85\%), 6-14 years old, participated in the study. Mean scores showed that the symptoms reduced after intervention significantly $(\mathrm{P}<0.01)$. The results indicated that parent training and behavioral therapy were effective in controlling ADHD children's behaviors.

Conclusions: The results of the present study can greatly benefit ADHD children since behavioral training may have a greater impact, than just the medication therapy on their social life.
\end{abstract}

Keywords: Behavior Therapy; Attention Deficit-Hyperactivity Disorder; Diagnostic and Statistical Manual of Mental Disorders

\section{Background}

Hyperactivity is a neurobehavioral condition, with symptoms of extreme restlessness, poor attention and impulse behaviors; a chronic disorder diagnosed by excessive activities, inattentive and impulsive behaviors, which often remains until adulthood. Evaluations indicate that $3 \%-7 \%$ of children who attend school and nearly $4 \%$ of adults are living with this disorder $(1,2)$. This disorder leads to major damages in friends and family relationships as well as school performance $(3,4)$. Teachers and parents do not know much about hyperactivity disorder; hence teachers should not reject students with attention deficit hyperactivity disorder (5-7). Parents of ADHD children often experience difficulty in managing their children's misbehavior (8). Although medication therapy is the standard treatment, strong evidence supports that use of stimulant drugs for treating core symptoms in ADHD children has little impact on their improvement. However, behavioral therapy alone has a lesser effect on symptoms and functions of ADHD children. Nevertheless, combination of medication and behavioral therapy seems to improve children's function (9). Use of medication alone can rarely resolve therapeutic needs in ADHD children. Moreover, Due to temporary therapeutic effects of medications on this disorder, there is now more emphasis on using behavioral therapy methods (10). ADHD therapists believe that feelings and conducts have mutual interactions; in addition, we have to consider symptoms, negative and positive aspects, family, school and community. Symptoms such as hyperactivity, attention deficit and impulsive behaviors respond to drugs, but medications are ineffective in controlling client's problems, thus use of non-medication treatments such as individual and group psychotherapy, behavioral therapy and parent training are required (11).

According to Mulqueen, parental interventions are effective treatments for preschool ADHD children. More-

Implication for health policy/practice/research/medical education:

This study evaluated the effectiveness of parent training and behavioral therapy on the behaviors of attention deficit hyperactivity disorder (ADHD) children. It is clear that behavioral therapy besides drug treatment can help psychologists and parents to manage ADHD children.

Copyright ( ) 2014, Health Promotion Research Center. This is an open-access article distributed under the terms of the Creative Commons Attribution License, which permits unrestricted use, distribution, and reproduction in any medium, provided the original work is properly cited. 
over, parent training and medication management have more effect on ADHD children (12). Zwi et al. point out that parent training has a positive effect on ADHD children's behaviors and may reduce parents' stress and increase their confidence (13). Furthermore, according to Kalantari study combination of behavioral parent training and medication therapy was more effective leading to significant improvement in subjects (14). Kangarlou et al. reported success of parent training in reducing behavioral problems of ADHD children (15). Van den Hoofdakker in his study showed that behavioral parent training would improve routine treatment in ADHD children and particularly reduce behavioral and internalizing problems, but it would not reduce ADHD symptoms or parental stress. Finally, behavioral parent training may reduce drug prescription (16). Studies on parental training claimed their effectiveness on ADHD, but such claims need scientific and controlled studies. Hence current research focused on the effectiveness of parent training and behavioral therapy on behaviors of ADHD children.

\section{Objectives}

The present study aimed to examine the effect of parent training and behavioral therapy on ADHD children. The current study hypothesis is that symptoms of ADHD children decrease significantly after parent training and behavioral therapy.

\section{Patients and Methods}

This study was a pretest-posttest study in a group of 61 children diagnosed with ADHD, aged 6 - 14 years, who were referred to the psychological clinic (Hamdelan), Zahedan, Iran in 2010. After the initial diagnostic interview based on Diagnostic and Statistical Manual of Mental Disorders, four edition-three revised (DSM IV), 61 ADHD children and their parents were selected randomly, provided they wanted to participate in therapeutic sessions. In addition, researchers were granted ethics of commitment permission at the beginning of the sessions. The first pretest was performed before parent training and behavioral therapy sessions, and the second one was immediately after parent training and behavioral therapy sessions. A questionnaire was designed by the researchers including diagnostic symptoms and features of ADHD, based on (DSM IV) which is one of the most reliable methods for assessing ADHD (17). This questionnaire had 71 items asked by a psychologist and replied by parents. Answer choices were "yes" or "no". If a client responded more than 71 checked items on ADHD test, it would indicate ADHD. Moreover, in this pretest, the minimum and maximum grades were 71 and 142 respectively (mean $=106.5$ ). Three children psychiatric specialists confirmed the content validity of the questionnaire. The validity of this test was measured by Alpha (90\%). The implemented therapeutic method was a behavioral treatment. Each subject was put under treatment during 16 sessions; 8 sessions for parent training and 8 sessions for child's behavioral disorders control. Each session lasted one hour, teaching the Barkley method. The detailed content of the sessions is as follows:

\subsection{Parent's Training Sessions}

- First session: explaining the disorders to parents to make them accept their child's disease,

- Second session: improving child-parents' interactions and examining their interactions,

- Third session: Reinforcing positive behaviors and neglecting negative behaviors,

- Forth session: examining behaviors and their changes resulting from the third session,

- Fifth session: examining obtained results after finding the most effective reinforcing, to select the best way,

- Sixth session: depriving and time out from fifth session reinforcing,

- Seventh session: extension of child's behavior control to the society in case of its establishment at home,

- Eighth session: concluding and analyzing the child's progress, referring to the file.

Children attended eight sessions so that the researchers could control their behaviors; parents helped them to perform this exercise. Synopses of the sessions are as follows:

\subsection{Behavioral Therapy; Ways Used in Controlling Children's Behavior}

- Providing some exercises, focusing on accuracy and slowing down of behavior,

- Providing a behavioral plan for establishing order and disciplinary sitting of children as well as reinforcing actions,

- Practicing special games for creating the order,

- Slowing down the speech and tone of voice,

- Controlling attention deficit disorder and distraction. SPSS software version 17 was used for data analysis and descriptive statistics, such as frequency, percentage and t-test.

\section{Results}

We aimed to study the effect of parent training and behavioral therapy on ADHD children. Sixty-one ADHD children and their parents were selected randomly in this study. The minimum and maximum ages of the subjects were 6 and 14 years, respectively. Each subject and his or her parents were provided with 8 sessions of behavioral therapy and 8 sessions of parent training. T-test was used to compare pretest and posttest results. As seen in Table 1 , the average age of subjects was eight years, and most of them were seven years old. Table 2 shows that most subjects were boys. Table 3 presented the age distribution of the subjects. Furthermore, Table 4 showed that the mean 
and scattering of ADHD have been decreased in the posttest, indicating the effect of parent training and behavioral therapy to reduce symptoms of ADHD children. Finally, the probability of accepting the null hypothesis was less than $0.05(\mathrm{P}<0.001)$.

\begin{tabular}{|c|c|c|}
\hline & Result & Mode \\
\hline Age & $8 \pm 2$ & 7 \\
\hline
\end{tabular}

\begin{tabular}{lc}
\hline \multicolumn{1}{l}{ Table 2. Frequency of Subjects Based on Gender ${ }^{\mathrm{a}}$} \\
\hline \multicolumn{1}{l}{ Frequency } \\
\hline Gender & $52(85.2)$ \\
Male & $9(14.8)$ \\
Female & $61(100.0)$ \\
\hline Total
\end{tabular}

${ }^{\mathrm{a}}$ Data are presented in No. (\%).

\begin{tabular}{lc}
\hline \multicolumn{2}{l}{ Table 3. Frequency of Subjects Based on Age } \\
\hline Age & Frequency \\
\hline $\mathbf{6}$ & $6(9.8)$ \\
7 & $26(42.6)$ \\
$\mathbf{8}$ & $7(11.5)$ \\
$\mathbf{9}$ & $8(13.1)$ \\
$\mathbf{1 0}$ & $4(6.6)$ \\
$\mathbf{1 1}$ & $3(4.9)$ \\
$\mathbf{1 2}$ & $3(4.9)$ \\
$\mathbf{1 3}$ & $3(4.9)$ \\
$\mathbf{1 4}$ & $1(1.6)$ \\
\hline Total & $61(100.0)$ \\
\hline a Data are presented in No.(\%).
\end{tabular}

Table 4. Comparison of Pretest and Posttest Results Using T-test $(\mathrm{n}=61)^{\mathrm{a}}$

\begin{tabular}{lcc}
\hline & Results & PValue \\
\hline Pre test & $119.75 \pm 10.92$ & $\leq 0.01$ \\
Post test & $94.63 \pm 14.07$ & $\leq 0.01$ \\
\hline
\end{tabular}

a Data are presented in Mean \pm SD.

\section{Discussion}

This study examined the impact of parent training and behavioral therapy on controlling children with attention deficit/hyperactivity disorder. Symptoms were al- leviated after the intervention by comparing mean values, and the differences were significant $(P<0.01)$. The outstanding point of this research is that parent training and behavioral therapy are effective on controlling behaviors of children with ADHD disorder. Comparing this study with a similar study performed by Barkly, parent training affects behavior management, educational intervention, and mostly self-efficacy of ADHD children (18). In addition, Herbert in his study entitled "A randomized controlled trial of a parent training and emotion socialization program for families of hyperactive pre-school aged children" assessed the effect of a 14week parent training and socialization program on 31 selected ADHD pre-school children. His results showed the effectiveness of parent training on reducing ADHD symptoms (19). Motoyama assessed 18 mothers with ADHD children after parent training program; results showed that parental stress was reduced, their self-esteem was increased, and parent-child relationship was improved (20). Adjunctive behavioral parent training is useful for mothers who have parental self-efficacy and for children with or without single-type (16). Strong evidence proves that parent training and cognitive behavioral therapy have useful effect on ADHD symptoms (2124). Frolich in a study assessed 18 children with ADHD and used six sessions of cognitive behavioral therapy as well as six sessions of parent training; results showed that ADHD symptoms were reduced at home and school (25). A review study performed by Fehlings revealed that cognitive behavior therapy would increase parent's perception about hyperactivity, also would improve children's self-esteem (26). Furthermore, Loren et al. examined 241 parents with ADHD children participated in eight sessions of group therapy; the results showed improvement in parent-child relationship (27).

According to the results of the relevant studies, behavior management skills have an impact on parenting practices. Therefore, it is recommended to teach these skills to parents having children with behavioral problems. Despite the problems of medication therapy, it is accepted as the main treatment in hyperactivity disorders. We can hardly convince parents to accomplish their children's psychotherapy. The results of the current study can be very helpful for hyperactive children since behavioral trainings can affect their social behaviors more than medication alone. As with all studies, this study bears some restrictions. One of the limitations of the current study was irregular attendance of fathers in sessions. Non-cooperation of fathers may harden the effective implementation of principles learned by mothers. Another limitation was personality characteristics of parents and their possible psychiatric disorders presumably affecting this study and its assessment. Moreover, comparing the efficacy of combination treatment with other methods such as bio-feedback techniques and behavioral interventions is recommended. 


\section{Acknowledgements}

The authors express their gratitude to subjects who helped us in this study.

\section{Authors' Contribution}

All authors equally took part in design, work, statistical analysis and manuscript writing.

\section{Financial Disclosure}

There were no conflicts of interests.

\section{Funding/Support}

This study did not receive any financial support.

\section{References}

1. American Psychiatric Association . Diagnostic and statistical manual of mental disorders: DSM-IV-TRß.United States: American Psychiatric Pub;2000.

2. Huang YS, Tsai MH. Long-term outcomes with medications for attention-deficit hyperactivity disorder. CNS Drug. 2011;25(7):539-54.

3. Barkley RA. Attention-deficit/hyperactivity disorder. New York: Guilford Press; 1998.

4. Hinshaw SP. Externalizing behavior problems and academic underachievement in childhood and adolescence: causal relationships and underlying mechanisms. Psychol Bull.1992;111(1):127-55.

5. Ghanizadeh A. Educating and counseling of parents of children with attention-deficit hyperactivity disorder. Patient Educ Couns. 2007;68(1):23-8.

6. Ghanizadeh A, Bahredar MJ, Moeini SR. Knowledge and attitudes towards attention deficit hyperactivity disorder among elementary school teachers. Patient Educ Couns. 2006;63(1-2):84-8.

7. Ghanizadeh A, Fallahi M, Akhondzadeh S. Disclosure of Attention Deficit Hyperactivity Disorder and its Effect on Rejection of Students by Teachers. Iran J Med Sci. 2009;34(4):259-64.

8. Campbell SB, March CL, Pierce EW, Ewing LJ, Szumowski EK. Hardto-manage preschool boys: family context and the stability of externalizing behavior. J Abnorm Child Psychol. 1991;19(3):301-18.

9. Brown RT, Amler RW, Freeman WS, Perrin JM, Stein MT, Feldman HM, et al. Treatment of attention-deficit/hyperactivity disorder: overview of the evidence. Pediatrics. 2005;115(6):e749-57.

10. Hughes JN. Cognitive behavior therapy with children in schools. New York: Pergamon Press; 1988.

11. Swanson JM, McBurnett K, Wigal T, Pfiffner LJ. Effect of stimulant medication on children with attention deficit disorder: a" review of reviews.". Except Child. 1993;60:154-62.

12. Mulqueen JM, Bartley CA, Bloch MH. Meta-Analysis: Parental In- terventions for Preschool ADHD. J Atten Disord. 2013.

13. Zwi M, Jones H, Thorgaard C, York A, Dennis JA. Parent training interventions for Attention Deficit Hyperactivity Disorder (ADHD) in children aged 5 to 18 years. Cochrane Database Syst Rev. 2011; (12):CD003018.

14. Kalantari M, Neshatdust H, Zarei M. The effect of parental education and drug therapy on symptoms of hyperactivity behavior children with attention disorders disorder/hyperactivity. J Psychol. 2002;18(2):185.

15. Kangarlou M, Lotfikashani F, Vaziri SH. The effectiveness of parent training in reduce behavior problems ADHD children.J Med Sci Islam Azad Univ. 2012;22(3):216-20.

16. Van den Hoofdakker BJ, van der Veen-Mulders L, Sytema S, Emmelkamp PM, Minderaa RB, Nauta MH. Effectiveness of behavioral parent training for children with ADHD in routine clinica practice: a randomized controlled study. J Am Acad Child Adoles Psychiatry. 2007;46(10):1263-71.

17. Mohammadsmaeeli E. [Cognitive behavior therapy for children with attention deficit/hyperactivity disorder].Tehran:Danjeh;2005.

18. Barkley RA. Psychosocial treatments for attention-deficit/hyperactivity disorder in children.J Clin Psychiatry. 2002;63 Suppl 12:36-43.

19. Herbert SD, Harvey EA, Roberts JL, Wichowski K, Lugo-Candelas $\mathrm{CI}$. A randomized controlled trial of a parent training and emotion socialization program for families of hyperactive preschoolaged children. Behav Ther. 2013;44(2):302-16.

20. Motoyama K, Matsuzaka T, Nagaoka T, Matsuo M. [The effect of parent training program on children with attention deficit hyperactivity disorders and/or pervasive developmental disorders]. No To Hattatsu. 2012;44(4):289-94.

21. Waxmonsky JG. Nonstimulant therapies for attention-defici hyperactivity disorder (ADHD) in children and adults. Essent Psychopharmacol.2005;6(5):262-76.

22. Ostberg M, Rydell AM. An efficacy study of a combined parent and teacher management training programme for children with ADHD. Nord J Psychiatry. 2012;66(2):123-30.

23. Fiks AG, Mayne S, Debartolo E, Power TJ, Guevara JP. Parental preferences and goals regarding ADHD treatment. Pediatrics. 2013;132(4):692-702.

24. Kienle X, Koerber S, Karch D. [Effectiveness of parent training for children with ADHD in routine clinical practice]. Prax Kinderpsychol Kinderpsychiatr. 2009;58(1):16-33.

25. Frolich J, Dopfner M, Berner W, Lehmkuhl G. [Treatment effects of combined cognitive behavioral therapy with parent training in hyperkinetic syndrome]. Prax Kinderpsychol Kinderpsychiatr. 2002;51(6):476-93.

26. Fehlings DL, Roberts W, Humphries T, Dawe G. Attention defici hyperactivity disorder: does cognitive behavioral therapy improve home behavior? J Dev Behav Pediatr.1991;12(4):223-8.

27. Loren RE, Vaughn AJ, Langberg JM, Cyran JE, Proano-Raps T, Smolyansky BH, et al. Effects of an 8-Session Behavioral Parent Training Group for Parents of Children With ADHD on Child Impairment and Parenting Confidence. J Atten Disord. 2013. 